\title{
Курдов Александр Георгиевич: ученый, учитель, наставник, коллега (к 100-летию со дня рождения)
}

\author{
B.А. Дмитриева ${ }^{凶}$ \\ Воронежский государственный университет, Российская Федераџия \\ (394018, г. Воронеж, Университетская пл., 1)
}

\begin{abstract}
Аннотация: Цель публикации - познакомить научную общественность с основными вехами жизни, научной и педагогической деятельности Александра Георгиевича Курдова - доктора географических наук, профессора, заведующего кафедрой гидрологии суши на географическом факультете Воронежского государственного университета

Maтериаль. В статье использованы материалы из личного архива автора, дочери А.Г. Курдова, воспоминания коллег и учеников.

Результаты и обсуждение. Главное внимание уделено научным исследованиям, выполненным А. Г. Курдовым в течение почти 60 лет трудовой деятельности на географическом факультете Воронежского государственного университета. В кратком изложении раскрывается основное научное направление - изучение минимального стока рек и временных водотоков Центрального Черноземья. Раскрывается содержание основных авторских публикаций, а также монографий с коллегами, инициатором и научным редактором которых был А.Г. Курдов. Приводится библиографический список основных работ. Обращается внимание на важные стороны учебной и общественной глубокое представление об А.Г. Курдове - ученом, руководителе структурной единицы образовательного учреждения, главе дружной семьи.

Заключение. Отмечается, что научные труды А.Г. Курдова востребованы, актуальны, пользуются интересом у широких слоев населения: ученых, студентов, школьников, краеведов.
\end{abstract}

Ключевые слова: кафедра, монография, гидрология суши, университет, ученый.

Для цитирования. Дмитриева В.А. Курдов Александр Георгиевич: ученый, учитель, наставник, коллега (к 100-летию со дня рождения) // Вестник Воронежского государственного университета. Серия: География. Геоэкология, 2021, № 3, c. 105-110. DOI: https://doi.org/10.17308/geo.2021.3/3608

Александр Георгиевич Курдов (16.04.192118.01.2015) прожил долгую, насыщенную событиями жизнь. В текущем году отметил бы свой 100-летний юбилей, до которого оставалось всего шесть лет! Он - доктор географических наук, профессор, выпускник кафедры геофизики физико-математического факультета Воронежского университета, стоял у истоков развития гидрологической специальности на географическом факультете. Путь в науку был не простым и не быстрым, по объективным и веским причинам [2].

А.Г. Курдов родился 16 апреля 1921 года в дер. Каширино Калужской области в семье отца, техника-строителя по профессии, и матери-домохозяйки. Ранние детские годы прошли в жи- вописном и щедром на природные краски крае, на берегах Десны, главного притока Днепра. Семья часто переезжала с места на место в связи с новыми назначениями отца. Александр Георгиевич имел возможность познакомиться с природными особенностями Калужской, Тульской, Белгородской, Челябинской областей. Любовь к природе зародилась еще в юношеские годы. Но талантливого молодого человека интересовали прежде всего точные науки.

После окончания школы в 1938 году Александр Георгиевич поступает на 1 курс физико-математического факультета Воронежского университета, где после 2 курса выбирает кафедру геофизики для дальнейшей профессиональной специализа-

(C) Дмитриева В.А., 2021

$\triangle$ Вера Александровна Дмитриева, e-mail: verba47@list.ru

Контент доступен под лицензией Creative Commons Attribution 4.0 License. 
ции. Кафедра геофизики была молодой, недавно сформировавшейся. Она стала развивать новое научное направление - физику русловых процессов - новый вектор науки, находящийся на стыке точных наук (физика, математика) и естественных наук о Земле (гидрология, физическая география). Ее возглавил приглашенный на должность заведующего кафедрой маститый практик-гидротехник, доктор технических наук, профессор Николай Петрович Чеботарев. Талантливый педагог, широкий эрудит, с тонким чувством юмора, обладавший неотразимой харизмой. Николай Петрович сумел организовать сплоченный коллектив и привлечь к обучению на кафедре пытливых, любознательных, увлеченных и добросовестных студентов. Среди них оказался и А.Курдов. Но завершить учебу по выбранной специальности ему удалось только в 1946 году.

В сентябре 1941 года А.Курдова призывают в армию и сразу же направляют для обучения специальности военного метеоролога-синоптика в Московский Высший военный гидрометеорологический институт. В звании «старший сержант» в 1943 году он заканчивает военное заведение и отправляется на фронт. Фронтовые дороги Александра Георгиевича пролегли по Украине, Молдавии, Румынии, Югославии, Болгарии и Австрии. Доблестная служба защитника Родины отмечена правительственными наградами: орденом Отечественной войны 2-й степени, медалями «За боевые заслуги», «За победу над Германией», юбилейными медалями.

За победным окончанием войны следовало возвращение в Воронеж, а с сентября 1945 года продолжение учебы по избранной специальности на кафедре геофизики физико-математического факультета университета. К этому времени вуз принимал своих бывших студентов.

Кафедрой геофизики руководил возвратившийся из эвакуации Н.П. Чеботарев. Талантливые студенты, среди которых был и А.Курдов, занимались под его руководством моделированием русловых потоков, имитацией русловых процессов, разработкой новых приборов и решением теоретических задач с выведением новых расчетных формул. В 1951 году кафедра переведена на географический факультет, а Н.П. Чеботарев за короткий срок сумел создать в университете новое научное и образовательное направление инженерную гидрологию.

С 1946 год берет отсчет педагогическая, научная и общественная деятельность А.Г. Курдова, которая продолжалась в общей сумме в течение 50 лет. Уже на географическом факультете им в 1952 году была защищена сначала кандидатская диссертация, а затем и докторская диссертация в 1970 году. Все научные исследования Алекандра Георгиевича были посвящены минимальному стоку рек Центрального Черноземья. Им выполнено гидрологическое районирование, разработаны расчетные формулы для определения минимумов речного стока в отсутствии данных наблюдений за элементами гидрологического режима. Свои исследования он оформил в виде монографий, не потерявших актуального значения и в наши дни. К ним относятся «Минимальный сток рек» (1970), «Реки Воронежской области» (1984), «Водные ресурсы Воронежской области (1995), «Проблемы Воронежского водохранилища» (1998).

В теоретическом аспекте интересна и значима монография «Минимальный сток рек (основные закономерности формирования и методы расчета)», вышедшая в издательстве Воронежского университета. Она явилась основой докторской диссертации, защищенной в 1970 году, и одновременно результатом и эпилогом многолетних исследований речного стока Центрального Черноземья. На 252 страницах монографии автором раскрыты вопросы формирования минимального стока, определяющего водные ресурсы рек в маловодное время года, предложена методика расчета его нормы, абсолютных минимумов летней и зимней межени при наличии и недостаточности гидрологических наблюдений. Последнее положение особенно актуально, так как гидрологическая сеть наблюдений редкая, а в конце 1980-х годов претерпевшая оптимизацию в виде существенного сокращения, примерно на $60 \%$ в Центральном Черноземье. Этот факт только усиливает актуальность исследований А.Г. Курдова.

Следует отметить, что в том же, 1970 году, вышла монография с таким же названием «Минимальный сток рек» весьма видного ученого тогда Ленинградского государственного гидрометинститута доктора географических наук, профессора А.М. Владимирова. В ней рассмотрены условия формирования и предложена схема расчета минимального стока при отсутствии данных наблюдений для территории бывшего Советского Союза. Исследования А.Г. Курдова и А. М. Владимирова шли параллельно, независимо друг от друга. Случалось, что авторы включались в полемику в научных статьях, возникали научные споры, разногласия, конфликтность мнений. 
Методика, разработанная на материалах сетевых гидрологических наблюдений в Центральном Черноземье, апробирована А.Г. Курдовым для подобных расчетов параметров минимального стока рек Башкирской АССР (на тот момент времени), а позже, за рамками монографии, и рек Челябинской области в тематике хоздоговорных работ, показала высокую степень достоверности результатов.

В названной монографии и предшествующих ей статьях А.Г. Курдов впервые ввел понятие «площадь нулевого стока», что означает площадь ежегодного или эпизодического пересыхания (перемерзания) - часть водосбора, которая не участвует в формировании речного стока в период минимальной водности. Она располагается выше истока реки. Крайней границей ее является линия водораздела. Выделение «площади нулевого стока» - принципиальный момент в методической схеме, который повышает точность расчета минимального стока. Величина ее не остается постоянной, меняется по гидрологическим районам для летних и зимних среднемесячных минимумов от 5 до 400 км² $^{2}$ а для минимальных летних и зимних абсолютных минимумов (экстремумов) - от 7 до

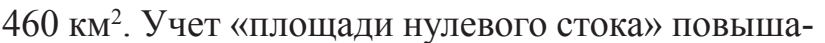
ет точность конечного результата расчета.

К значимым научным результатам принадлежит гидрологическое районирование Центрального Черноземья, выполненное автором в 1966 году. Александр Георгиевич подошел скрупулезно к обоснованию гидрологических районов, опираясь на физико-географическое (ландшафтное) районирование Ф.Н. Милькова (1961), геоморфологическое - И. Н. Ежова (1957), почвенно-климатическое - П.Г. Адерихина (1961). На территории ЦЧО выделено 9 гидрологических районов, из которых четыре расположены на Среднерусской и один на Калачской возвышенностях, три - на Окско-Донской низменной равнине, и один занимает часть западных склонов Приволжской возвышенности. Гидрологические районы отличаются друг от друга формами рельефа, количеством атмосферных осадков, годовым стоком, водообильностью подземных водоносных горизонтов, густотой речной сети и другими признаками. Подробное описание районов приводится в коллективной монографии под редакцией А.Г. Курдова «Картирование вероятностного стока рек» (1987).

К востребованным на сегодняшний день публикациям следует отнести монографию А. Г. Курдова «Реки Воронежской области (водный режим и охрана)» (1984). Ее основу составляют многолетние авторские исследования водного режима и изменчивости гидрологических параметров во времени и пространстве, гидрографическое описание малых и средних рек Воронежской области. Подобных монографий по бассейну Дона на территории Воронежской области до выхода данной публикации не существовало Ее появление ликвидировало пробелы гидрологических сведений. За прошедшие почти 40 лет с момента выхода монографии, несмотря на современные изменения в речной сети в связи с антропогенными и особенно климатическими факторами, она находит интерес у широкой читательской аудитории разного возраста и уровня образования. Книга написана научным, лаконичным, доступным языком, поэтому к ней обращаются ученые-природоведы, студенты и школьники.

К персональным научным работам А.Г. Курдова относится монография «Водные ресурсы Воронежской области: формирование, антропогенное воздействие, охрана и расчеты» (1995). Автор продолжил гидрографическое описание рек, не вошедших в предыдущее издание, оценил водные ресурсы Воронежской области, картографическим способом представил пространственную изменчивость водных ресурсов. Особое внимание уделено антропогенному воздействию на формирование водных ресурсов. К этому времени хозяйственная нагрузка на речные водосборы и русла рек достигла своего апогея: спрямление русел, сведение лесов, водная и почвенная эрозия, заборы воды из рек, эвтрофикация русел, загрязнение рек, что существенно ухудшало экологическое состояние водных объектов.

Как итог антропогенизации речных бассейнов А.Г. Курдов называет исчезновение 28 рек с площади Воронежской области, произошедшее за 1950 - 1997 годы. Сегодня мы можем к этому числу деградированных, исчезающих и исчезнувших добавить еще немалое количество рек Воронежской области, а причиной процесса является не только антропогенное воздействие, но и современная динамика климата [1].

Не остались без внимания и водоемы Воронежской области: озера (Погоново, Кременчуг, Жировское, Ильмень и др.), затоны (Вислинский, Богатый), болота (в общей массе), пруды и водохранилища.

В этой монографии Александр Георгиевич впервые предложил рейтинговый показатель антропогенной нагрузки на водные объекты и водные ресурсы, который включает 26 «гидрологических и ландшафтных показателей», теория которого получила свое развитие в последующей публикации. 


\section{В. А. Дмитриева}

Более подробно методика определения рейтингового показателя водного объекта и новая рейтинговая концепция антропогенного воздействия рассмотрена А.Г. Курдовым в его монографии «Проблемы Воронежского водохранилища» (1998). Книга вышла с посвящением 80-летию Воронежского государственного университета. К моменту выхода монографии искусственный водоем существовал уже более 25 лет. За это время возник целый ряд гидроэкологических проблем, к которым в первую очередь относились низкий водообмен в водохранилище, слабая проточность водоема и качество воды, зависящее как от природных факторов, так и хозяйственной деятельности на водосборе и в самом водоеме.

На примере реки Усмань (Усманка) выполнен расчет рейтинга антропогенной нагрузки. Александр Георгиевич доказал, что суммарный рейтинговый показатель нагрузки по длине реки непостоянен: в верховье составляет $88 \%$, а в низовье - $31 \%$. Методика подсчета рейтингового показателя требует от исполнителя соблюдения тщательности и щепетильности, поскольку достоверным результат может быть только при максимальном учете внешних факторов воздействия на водный объект.

Уже находясь на пенсии, А.Г. Курдов написал свою заключительную работу «Родники Воронежской области (формирование, экология, охрана)» (2000). В наши дни у Александра Георгиевича много продолжателей изучения этих исключительно интересных природных водных источников. Сегодня исследованием родников занимаются многие любители природы. Тема изучения родников является популярной в школьных проектах по географии, биологии, химии.

Bce монографии и многочисленные статьи, о которых в данном обзоре не идет речь, написаны научным и одновременно художественным языком. Александр Георгиевич не любил длинных предложений, пространных рассуждений. Его язык строг, красив, точен, понятен и доступен.

Научную деятельность А.Г. Курдов сочетал с административной и учебной работой. С 1967 года А.Г. Курдов возглавил кафедру гидрологии суши на географическом факультете, которой бессменно руководил в течение 20 лет. Он создал мощный преподавательский корпус, вырастивший и давший путевку в большую профессиональную жизнь многим сотням выпускников, разлетевшихся по всей бывшей большой стране и за ее рубежи. Большим достижением руководите- ля кафедры было обеспечение производственных практик студентов в производственных коллективах проектно-изыскательских и сетевых гидрологических организаций. Студенческая практика в течение 4-х месяцев с апреля по июль на водных объектах нашей страны давала знания, которые в разы увеличивали гидрологическую грамотность студентов, приносила огромное удовлетворение от собственной значимости и поднимала авторитет и престиж профессии. Зачастую выпускники после окончания университета распределялись в места прохождения практик и впоследствии долго и успешно в них работали. До сих пор работают мои сокурсники в Казани, Уфе, Челябинске, Киеве, а выпускники кафедры, ученики А.Г. Курдова, в разных уголках страны.

Многие годы А.Г. Курдов-преподаватель читал фундаментальную в подготовке инженера-гидролога дисциплину - гидрометрию. В течение пяти семестров под его руководством осваивались методы полевых наблюдений и измерений гидрологических характеристик, построения кривых расходов воды и расчета стока при различных гидрологических ситуациях, осваивались специальные методы изучения водных объектов, изучались гидрологические приборы и оборудование. Этот курс закреплялся учебной практикой после 2 курса в течение 6 недель на Дону, на базе заповедника «Галичья гора», а затем уже и производственной практикой, о которой шла речь выше.

Автор этих строк начинала свою преподавательскую деятельность с курса «Гидрометрия и техника безопасности», который А.Г. Курдов передал мне, своей ученице, как оказалось, на долгие 40 лет. Я признательна и благодарна Александру Георгиевичу за это. Основы гидрологических знаний, которые закладываются в «Гидрометрии», позволили мне вести и другие фундаментальные в подготовке инженера-гидролога дисциплины, такие как «Речной сток и гидрологические расчеты», «Водно-балансовые исследования», для которых «Гидрометрия» подстилающая дисциплина.

Помимо названного курса «Гидрометрия» Александр Георгиевич читал спецкурс «Минимальный сток», основой которого были его собственные исследования.

Наряду с учебной, научной, административной работой Александр Георгиевич был активным общественником. В разные годы он возглавлял партийную организацию факультета, научное общество «Знание», осуществлял профсоюзную 
деятельность, долгие годы руководил научным студенческим кружком, впоследствии передав этот вид деятельности доценту кафедры гидрологии суши М. П. Колпачевой.

В 1987 году А.Г. Курдов по возрасту оставил руководство кафедрой, да вскоре и подготовка студентов-гидрологов прекратилась, а кафедра перепрофилировалась на другую специальность.

В 1996 году А.Г. Курдов вышел на заслуженный отдых, но постоянно поддерживал связь с факультетом, которому отданы годы жизни, активно общался с выпускниками кафедры гидрологии разных лет, продолжал исследовательскую деятельность, оставляя свой добрый след в публикациях. Вехи его жизни и деятельности отражены в многостраничной монографии об отечественных гидрологах [3], газетных статьях разных лет, в публикации автора этих строк [1].

Александр Георгиевич еще в студенчестве создал крепкую, дружную семью. Его жена, Раиса Ивановна, сокурсница, работала в начале преподавательской деятельности на кафедре гидрологии суши, а затем старшим преподавателем на кафедре гидравлики политехнического института вплоть до выхода на пенсию. Ушла из жизни на 10 суток раньше мужа, в том же 2015 году.

В семье две дочери: Людмила Александровна - физик по образованию. Живет с семьей в Воронеже; Елена Александровна - математик по образованию. Живет в Оттаве. Три взрослые внучки живут в России, Германии и Канаде.

Библиографический список монографических

публикаций А. Г. Курдова и коллектива сотрудников кафедры гидрологии суши

1. Курдов А.Г. Минимальный сток рек (Ocновные закономерности формирования и методы расчета). Воронеж: Издательство Воронежского государственного университета, 1970. 252 с.

2. Курдов А. Г. Реки Воронежской области (водный режим и охрана). Воронеж: Издательство Воронежского государственного университета, 1984. 164 c.
3. Курдов А.Г. Водные ресурсы Воронежской области: формирование, антропогенное воздействие, охрана и расчеты. Воронеж: Издательство Воронежского государственного университета, 1995. 224 c.

4. Курдов А. Г. Проблемы Воронежского водохранилища. Воронеж: Издательство Воронежского государственного университета, 1998. 168 с.

5. Курдов А.Г. Родники Воронежской области (формирование, экология, охрана). Воронеж: Издательство Воронежского государственного университета, 2000. 128 с.

Публикации под редакцией А.Г. Курдова в хронологической последовательности

6. Карты стока рек и временных водотоков (на примере центрально-черноземных областей). Под ред. А. Г. Курдова. Воронеж: Издательство Воронежского государственного университета, 1975. 144 с.

7. Расчеты стока рек и временных водотоков. Под ред. А.Г. Курдова. Воронеж: Издательство Воронежского государственного университета. 1979. $201 \mathrm{c.}$

8. Картирование вероятностного стока рек (на примере центрально-черноземных областей) / А. Г. Курдов, В. А. Дмитриева, В. В. Протопопов и [др.]. Воронеж: Издательство Воронежского государственного университета, 1987. 188 с.

\section{СПИСОК ЛИТЕРАТУРЫ}

1. Дмитриева В.А. Гидрологическая изученность Воронежской области. Каталог водотоков. Воронеж: ИПЦ Воронежского государственного университета, 2008. 225 c.

2. Дмитриева В.А. А.Г. Курдов. Слово об учителе // Вестник Воронежского государственного университета. Серия: География. Геоэкология, 2004, № 2, с. 86-89.

3. Отечественные гидрологи ХХ в. Историко-биографическое описание: монография / под ред. Д.Е. Клименко. Екатеринбург: Уральский рабочий, 2018. с. 443-445.

Конфликт интересов: Автор декларирует отсутствие явных и потенциальных конфликтов интересов, связанных с публикацией настоящей статьи.

Поступила в редакциюо 02.06.2021 Принята к публикации 03.09.2021 


\title{
Kurdov Alexander Georgievich: Scientist, Teacher, Mentor, Colleague (to the 100th Anniversary of His Birth)
}

\author{
V.A. Dmitrieva ${ }^{\bowtie}$ \\ Voronezh State University, Russian Federation \\ (1, Universitetskaya Pl., Voronezh, 394018)
}

\begin{abstract}
The purpose of the publication is to acquaint the scientific community with the main milestones of life, scientific and teaching activities of Alexander Georgievich Kurdov, Doctor of Geographical Sciences, Professor, Head of the Department of Land Hydrology at the Geography Department of Voronezh State University

Materials. Materials from personal archive of the author, the daughter of A.G. Kurdov, memoirs of colleagues and pupils are used in the article.

Results and Discussion. Major attention is given to the scientific research work carried out by A. G. Kurdov for almost 60 years of his labor activity at geographical faculty of Voronezh State University. The main scientific direction - study of the minimum flow of rivers and temporary streams of the Central Black Soil Region - is briefly described. The contents of the main author's publications as well as monographs with colleagues initiated and scientifically edited by A. G. Kurdov are disclosed. A bibliographical list of the main works is given. Attention is drawn to important aspects of teaching and public insight into A. G. Kurdov as a scientist, head of a structural unit of an educational institution, head of a close-knit family.

Conclusion. It is noted that scientific works of A. G. Kurdov are demanded, actual, enjoy interest at wide layers of the population: scientists, students, pupils, local historians.

Key words: chair, monograph, land hydrology, university, scientist.

For citation: Dmitrieva V.A. Kurdov Alexander Georgievich: Scientist, Teacher, Mentor, Colleague (to the 100th Anniversary of His Birth). Vestnik Voronezskogo gosudarstvennogo universiteta. Geografia geoekologia, 2021, no. 3, pp. 105-110. (In Russ.) DOI: https://doi.org/10.17308/geo.2021.3/3608
\end{abstract}

\section{REFERENCES}

1. Dmitrieva V.A. Gidrologicheskaya izuchennost' Voronezhskoi oblasti. Katalog vodotokov [The State of Hydrological Exploration of Voronezh Region. Catalogue of Water Courses]. Voronezh: Voronezhskii gosudarstvennyi Universitet, 2008. 225 p. (In Russ.)

2. Dmitrieva V.A. A.G Kurdov. Slovo ob uchitele [A. G. Kurds. A word about the teacher]. Vestnik Voronezhskogo gosudarstvennogo universiteta. Seria: Geografia. Geoekologia. 2004, no. 2, pp. 86-89. (In Russ.)

\section{Дмитриева Вера Александровна}

Доктор географических наук, профессор кафедры природопользования факультета географии, геоэкологии и туризма Воронежского государственного университеTa, г. Воронеж, Российская Федерация, ORCID: 00000002-8464-3593, e-mail: verba47@list.ru
3. Otechestvennie gidrologi $X X$ v. Istoriko-biograficheskoe opisanie: monografiya [Domestic hydrologists of the XX century. Historical and biographical description: monograph]. Pod red. D.E. Klimenko. Yekaterinburg: Ural'skiy rabochiy, 2018. pp. 443-445. (In Russ.)

Conflict of interests: The author declares no information of obvious and potential conflicts of interest related to the publication of this article.

Received: 02.06.2021 Accepted: 03.09.2021

Vera A. Dmitrieva

Doc. Sci. (Geogr.), Prof. of the Department of Nature Management, Faculty of Geography, Geoecology and Tourism, Voronezh State University, Voronezh, e-mail: verba47@ list.ru

(C) Dmitrieva V. A., 2021

$\square$ Vera A. Dmitrieva, e-mail: verba47@list.ru

The content is available under Creative Commons Attribution 4.0 License. 